\title{
A System to Determine the Effect of Change Order for Roads Projects on Execution Time
}

\section{$\underline{\text { Saif Saad Mohammed Khuder }}^{{ }^{*}}$, Abdul Rahman Adnan Ibrahim ${ }^{2}$, Osama Abd Al-Ameer Eedan 3}

1 Master student - Civil Eng. Dept., College of Engineering, Tikrit University.

2 Civil Eng. Dept., College of Engineering, Tikrit University.

3 Civil Eng. Dept., University of Technology.

\section{Keywords:}

road projects, change orders, increased project time, additional cost, equation modeling, and computer program

\section{A R T I C L E I N F O}

\begin{tabular}{ll}
\hline Article history: & \\
Received & 03 June. 2021 \\
Accepted & 28 Aug. 2021 \\
Available online & 17 Jan. 2022
\end{tabular}

C2022 COLLEGE OF ENGINEERING, TIKRIT UNIVERSITY. THIS IS AN OPEN ACCESS

ARTICLE UNDER THE CC BY LICENSE

http://creativecommons.org/licenses/by/4.0/

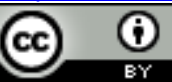

Citation: Khuder SSM, Ibrahim AA, Eedan OA. A System to Determine the Effect of Change Order for Roads Projects on Execution Time. Tikrit Journal of Engineering Sciences 2022; 29(1): 26-35. http://doi.org/10.25130/tjes.29.1.3

\section{A B S T R A C T}

The current study aims to create a computer program that estimates the time required to complete the additional work due to the change command by evaluating the cost of these works. A set of mathematical formulas and arithmetic equations are utilized for programming purposes. Furthermore, the difference of time due to the change order $(\mathrm{Y})$ was calculated depending on the cost of these works (X). Moreover, these equations were developed by statistical analysis of the data collected from change orders for roads in Salah alDin Governorate. Then the program was verified and evaluated by a group of engineers through doing a survey. Briefly, the practical benefit of the program was excellent, with a recurrence rate of (50\%) based on the evaluation of these engineers. The advantage of using the program in future projects was good, with a recurrence rate of (49.8\%). Also, the most frequent works in change orders for road projects at Salah al-Din Governorate has been specified and concluded. It was found that the works of operating and cleaning roads were repeated at a rate of (30\%) in the change orders. Moreover, the earthworks were repeated at a rate of (20\%), and the drainage works repeated at a rate of $(20 \%)$. These results are used to focus on these works when preparing schedules of quantities for future projects to avoid errors in estimating quantities and the problem of increasing time and cost resulting from change orders of these projects.

${ }^{*}$ Corresponding Author: Saif Saad Mohammed Khuder, Master student - Civil Eng. Dept., College of Eng., Tikrit University.. 


\section{نظام لتحديد أثر أمر التغيير على الزمن اللازم لتتفيذ مشاريع الطرق

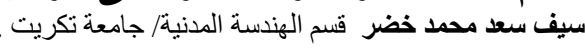

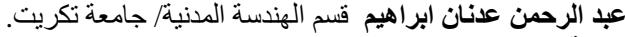 \\ اسامة عبد الامير عيدان قسم الهندسة المدنية / الجامعة التكنلوجية.}

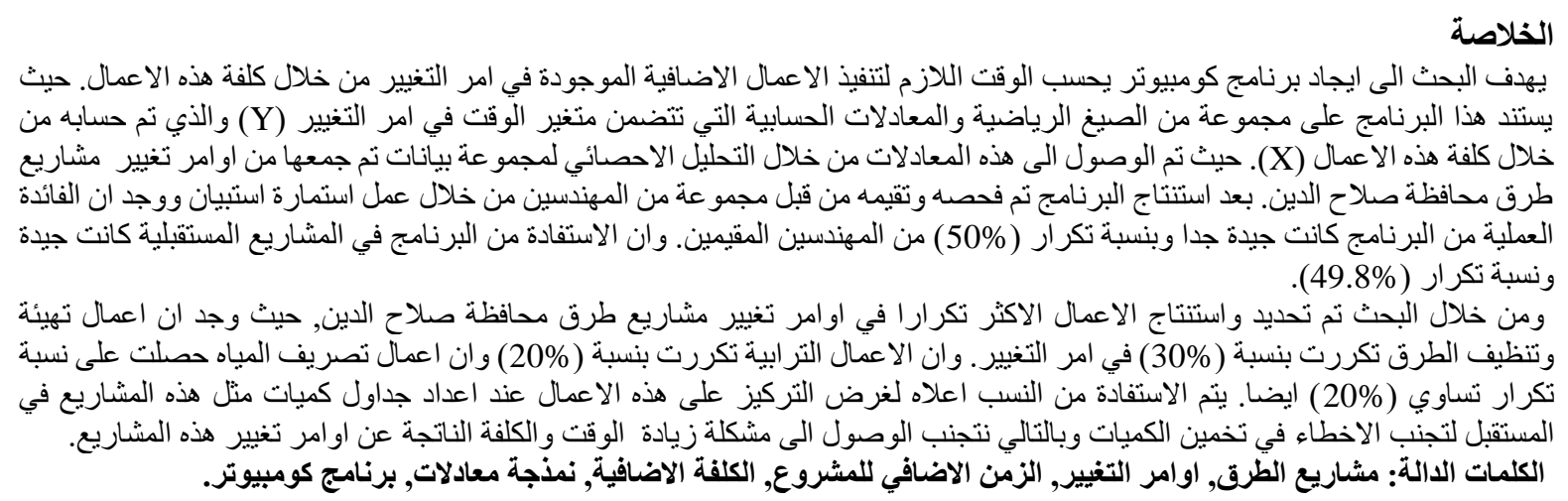

\section{Introduction.}

Almost no construction project occurs without changes in the initial plans and design during the project implementation period. This change must be controlled through its account and organization with a legal contract called (Change or Variation Order) attached to the original contract of the project. The time required to implement the works is a point of dispute between the owner and the contractor. Changes are caused by several factors, the most important of which are changing plans by the owner, changing the scope of the project at the owner's request, designing errors and omissions, and poor design of project plans [1]. Most common reasons for change orders include the introduction of alternatives, importing materials into the local market, the availability of other options that add value to the project, the project owner's request for a renewal of work specifications, the consulting engineer's opinion, and observations on the work, and his effort to develop the project [2]. Lack of appropriate equipment and mechanisms, the lack of skillful hands, the complexity of the design, changing the project schedule, and impeding the rapid decision-making process are among the reasons that lead to the occurrence of the change order [3]. The owner's financial problems, the exclusive right to make decisions, the contractor's lack of involvement in the design process, the project's short design period, and the project's challenging climatic conditions are just several of the reasons why a change order must be prepared and requested. [4, 5].

In that order, a person who started requesting the suspension of change orders was the project owner, consulting engineers, contractor, and other external circumstances [6]. To avoid contacting the change order, the attention must be on the design and planning phase of the project, by carefully defining the owner's requirements so that errors and shortages in quantities do not occur during the implementation phase and thus lead to additional work or the demolition of completed works, which increased project costs and delays. Also, other works requests may occur as a result of the disagreements. This is accomplished through effective collaboration among all parties and project engineers from all disciplines (civil - architectural - electrical mechanical) [7].

The most critical effects expected to appear on the original project which results from change orders are the increase in the cost needed to implement the project over the cost of the original contract, as well as the increase in the time required to implement the project over the time planned in the actual project.[1$5]$. Because of the change order, the cost of the studied projects increased by (31\%) over the cost of the original contract. The increase in time over the contract's original duration was equal to (29\%) [8]. The impact of the change order on the project's life cycle is reflected by an increase in the cost of purchases of (28.7\%), a time delay in the complete plan of (28.1\%), a deterioration in the project's work efficiency of (11.8\%), and a delay in paying the contractor and workers' dues of (9.2\%) [9]. As for solving the problem of estimating works time in a change order, this study is current to determine the effect of a change order for roads projects on execution time.

There is a direct relationship between the occurrence of change orders and the increase in the completion time of the studied projects. The percentage of increase in time ranged from (22 200 )\% due to change orders. On the other hand, the cost analysis showed a rise of $(42.86-2.67 \%)$ due to change orders. [10]. A mathematical relationship was found between the cost of the work in the change order. The time required to implement these works for the projects of hospitals in central and southern Iraq, where the relationship was direct between them, the time required increases with the increase in the cost of the change order [11]. As a result of this study, a suitable means has been provided to clarify 
the factors that lead to the occurrence of change orders and to predict their effects on construction projects in the Gaza Strip. This means there is a simulation model of change orders and their impact on the success of construction projects. The models are designed to show the change order's cost, time, and productivity. The results given by the model were accurate by (97.02\%) for predicting the increase in cost, and the expectation of extending the time was accurate by (95.75\%) [12].

Furthermore, the difference of time due to the change order $(\mathrm{Y})$ was calculated depending on the cost of these works (X). So, the current study aims to create a computer program that estimates the time required to complete the additional work due to the change command by evaluating the cost of these works. A set of mathematical formulas and arithmetic equations are utilized for programming purposes. Furthermore, these equations were developed by statistical analysis of the data collected from change orders for roads in Salah al-Din Governorate.

The study's limitations include defining the location of road projects for Salah al-Din Governorate and estimating its time to complete them between 2001 and 2020. In addition, knowing the exchange rate of one dollar at 1190 Iraqi dinars is necessary because some projects are priced in dollars.

\section{Research Methodology.}

The following points outline the research methodology:

1- Selecting road projects in Salah El-Din Governorate to analyze change orders.

2- Collecting data from the road projects represented in the cost of the works in the change order and the time required to implement these works. Data are collected through a field visit to each project and its files, and the cost and time of each work

(earthworks, asphalt works, water drainage, road preparation and cleaning works, etc.) are taken from the change order.

3- Finding the relationship between the time variable (Y-axis) and the cost variable (Xaxis) by examining the correlation coefficient between the two variables and finding the best-curved line (in the method of least squares) that passes through the drawn points. The curve is drawn between the time and cost variable represents the relationship between them, and the equation that describes this curve can be found.

4- Using the Statistical Package for Social Sciences (SPSS) program to facilitate access to mathematical equations and formula that calculates the time $(\mathrm{Y})$ in terms of cost (X).

5- Converting the discovered equations into a computer program makes it easier to use them in future projects when calculating time.

6- Evaluation of the program by a group of engineers working in the road projects sector in Salah al-Din Governorate.

7- Determining the most familiar works in road project change orders may be focused on during the design stage, generating bills of quantities, and managing their amounts so that they do not appear in future projects.

\section{Case Study and Data Collection.}

The road projects in Salah El-Din Governorate were selected. A site visit to each project, evaluating its files, studying the change orders for each of them, and collecting data expressed in the cost of each task included under the change order and the time required to perform this work was selected to research their change orders, as indicated in Table 1.

Table 1.

Data collection for Salah al-Din Governorate road projects

Project name: Construct (45.02 Km.) from (Samarra - Addor - Al Alam) Road

\begin{tabular}{cccc}
\hline Seq. & Type of work & Cost of work(I.D.) & Work time (day) \\
\hline 1 & $\begin{array}{c}\text { Equipping the Resident Engineer } \\
\text { Department with the field testing } \\
\text { laboratory with two cars. } \\
\text { Shoulders works on both sides of } \\
\text { the road. }\end{array}$ & $36,000,000$ & 0 \\
3 & $\begin{array}{c}\text { Asphalt concrete works, the } \\
\text { thickness of } 7 \text { cm. }\end{array}$ & $31,920,000$ & 84 \\
4 & $\begin{array}{c}\text { Asphalt concrete works, the } \\
\text { thickness of } 5 \text { cm. }\end{array}$ & $67,698,750$ & 6 \\
\hline
\end{tabular}




\begin{tabular}{|c|c|c|c|}
\hline 5 & $\begin{array}{l}\text { Shoulder leveling work on both } \\
\text { sides of the road. }\end{array}$ & $39,450,000$ & 7 \\
\hline 6 & $\begin{array}{l}\text { Asphalt concrete works, the } \\
\text { thickness of } 7 \mathrm{~cm} \text {. }\end{array}$ & $221,100,000$ & 40 \\
\hline 7 & $\begin{array}{l}\text { Asphalt concrete works, the } \\
\text { thickness of } 5 \mathrm{~cm} \text {. }\end{array}$ & $145,250,000$ & 26 \\
\hline \multicolumn{4}{|c|}{$\begin{array}{c}\text { Project name: Maintenance project for a }(64 \mathrm{~km}) \text { road, Dujail - Samarra, and (32 km) } \\
\text { from Samarra - Dhuluiya road. }\end{array}$} \\
\hline Seq. & Type of work & Cost of work(I.D.) & Work time (day) \\
\hline 1 & $\begin{array}{l}\text { Remove debris and debris along the } \\
\text { way. }\end{array}$ & $123,000,000$ & 60 \\
\hline 2 & Removing the damaged asphalt. & $20,910,000$ & 16 \\
\hline 3 & $\begin{array}{l}\text { Removing the affected space and } \\
\text { shoulders. }\end{array}$ & $11,562,000$ & 60 \\
\hline 4 & Burial work. & $9,840,000$ & 30 \\
\hline 5 & Asphalt concrete works. & $14,760,000$ & 17 \\
\hline 6 & Asphalt layer $6 \mathrm{~cm}$ thickness. & $7,380,000$ & 9 \\
\hline 7 & $\begin{array}{c}\text { The joists work with a length of } 5 \\
\text { meters. }\end{array}$ & $12,300,000$ & 45 \\
\hline 8 & Extension joints. & $7,380,000$ & 15 \\
\hline 9 & Concrete works over the tributaries. & $854,181,750$ & 60 \\
\hline
\end{tabular}

Following the data collected from the projects, they were divided into categories based on the nature of work (earthworks, asphalt cladding works, water drainage works, road preparation and cleaning works, and other works).

\section{Data analysis and results discussion.}

To reach the mathematical equations that link the cost of works (X) to the time needed to carry out these works (Y), the (least-squares method) is used by drawing the two variables on their axes, which are represented by a set of points on the plane of axes then finding the best curve that passes through all the plotted points. Therefore we can say that this curve represents these points. Then the equation of this curve is found, whether it is (linear, quadratic, or cubic) based on some statistical concepts such as (correlation coefficient, scatter diagram, ANOVA analysis) [13].

\subsection{Correlation coefficient.}

It is a statistical concept for measuring the extent and strength of the relationship between two variables, and it is expressed as a value between $(+1$ and -1$)$. The value $(+1)$ indicates a (positive) relationship between the two variables (X and Y). The value $(-1)$ indicates that there is an (inverse) relationship between the two variables (X and Y). The zero (o) means no relationship between the two variables [14].

\subsection{Scatter diagram.}

It is a primary means of identifying the type of association between the two variables (X and Y), whether the association is strong, weak, or nonexistent. And whether the relationship is linear or nonlinear, positive or negative. It is valid if the two variables are quantitative. It should be noted that this is an elementary method as it only helps to know the type of association. The scattering figure aims to graphically represent the values of the two variables on their axes, where the first variable $(\mathrm{X})$ is placed on the horizontal axis and the second variable $(\mathrm{Y})$ on the vertical axis, and each pair of values are represented by a point on the plane.[15].

\subsection{Analysis of Variance (ANOVA).}

It is a set of statistical models and values that compares the average of different statistical communities by dividing the sum of the observed variance among them into different parts. The analysis of variance is based on the Fisher (F) distribution, which is a continuous distribution. This distribution was adopted by the English statistician Fisher, so it is sometimes known as the Fisher coefficient. The Fisher coefficient $(F)$ is used to compare and choose between mathematical models and equations (linear, quadratic, cubic.) It represents a predictive equation for the curve that passes through the oil plotted on the plane between the two axes $(\mathrm{X}, \mathrm{Y})[16]$. 


\subsection{Analysis and results.}

The (SPSS) program was used to analyze the data. After entering the work cost, which represents the (X) axis, and the time required to carry out these works represents the $(\mathrm{Y})$ axis. The program gives the results described by the analysis of variance (ANOVA) table and the scatter diagram for each type of work whose duration is to be found.

The expected works in the change orders of road projects are:

A-Road preparation and cleaning work.

B-Earthworks.

C-Cladding works with asphalt or concrete layers.

D-Water drainage works.

E-Other works.

Other works include security controls, sonar works, and the supply of the resident engineer departments.
A-Road preparation and cleaning work.

Finding the equation that relates the cost of the preparation and cleaning works of road projects to the time of those works is done by choosing from among several equations (linear - quadratic - cubic), by testing the greater Fisher coefficient (F) and the level of significance less than (o.o1), which are found in the analysis table (ANOVA). Or through the scattering form directly, where the best-curved line chosen passes the points are drawn $[15$, 16].

Table 2. shows the value of the Pearson correlation coefficient $(+0.963)$, which means that the relationship between the two variables is a solid direct relationship. It means that the time added in the change order increases with the increase in the cost of work in the same order.

Table 2.

ANOVA and Correlation Output, for Additional Preparation and Cleaning Works.

\begin{tabular}{cccc}
\hline Equation type & $\begin{array}{c}\text { Correlation } \\
\text { coefficient }\end{array}$ & $\begin{array}{c}\text { Fisher coefficient } \\
\text { F }\end{array}$ & Significance level \\
\hline Linear & +0.963 & - & - \\
Quadratic & +0.963 & - & - \\
Cubic & +0.963 & - & - \\
\hline
\end{tabular}

If the values of (F) are not given by the (SPSS) program as in the above table (because all equations have the same statistical significance), the scatter diagram is inferred to choose the type of equation by observing the curve closest through the points [17], as shown in Fig.1. below.

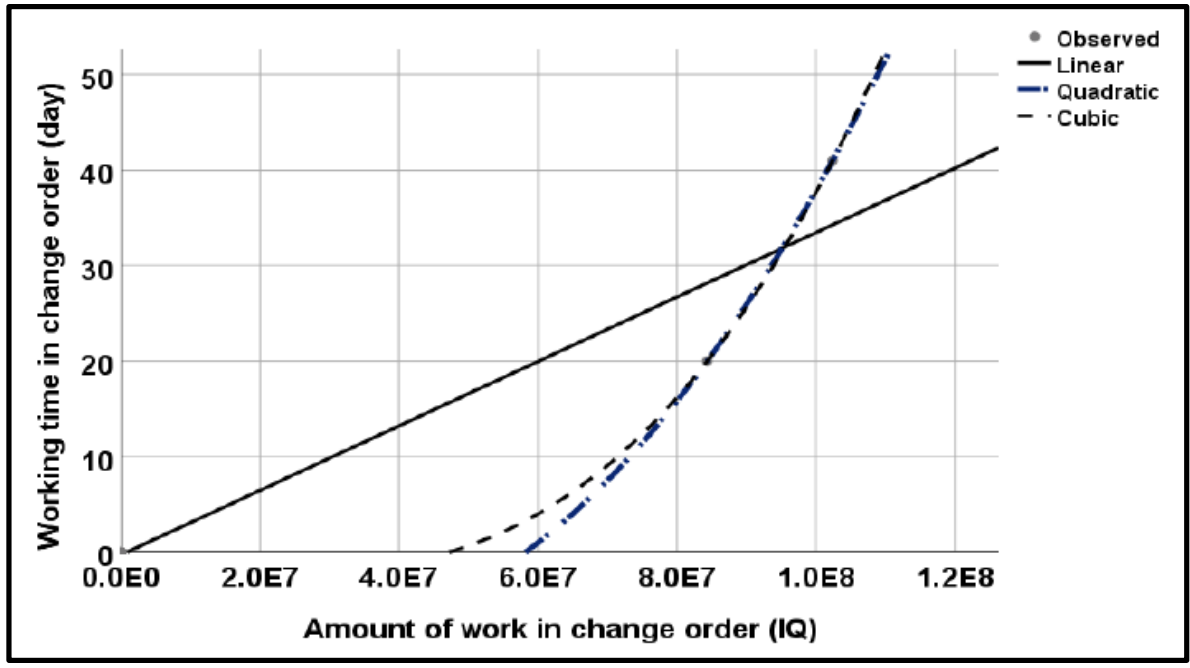

Fig. 1. Scatter Diagram for Additional Preparation and Cleaning Works and its Time.

From Fig.1 . we notice that the curve of the second degree (quadratic) is the closest and most passing through the points between the cost axis (X) and the time axis $(\mathrm{Y})$, so the equation of the curve is chosen from the second degree (quadratic) to represent the data of these works [17]. The equation of the curve is as follows:

$$
y_{1}=a_{0}+a_{1} x_{1}+a_{2} x_{1}^{2}
$$

Where: 
$y_{1}$ : Time for preparing and cleaning works in change order (Day).

$x_{1}$ : Cost of preparing and cleaning works in change order (I. D.).

$\boldsymbol{a}_{0}, \boldsymbol{a}_{1, \text { and }} \boldsymbol{a}_{2}$ : Equation coefficients.

The (SPSS) program gives the values of $\left(\boldsymbol{a}_{0}, \boldsymbol{a}_{1, \text { and }} \boldsymbol{a}_{2}\right)$ after analysis and choosing the type of equation as follows:

$$
\begin{aligned}
& a_{0}=1.066 * 10^{-14} \\
& a_{1}=-5.268 * 10^{-7} \\
& a_{2}=9.055 * 10^{-15}
\end{aligned}
$$

So, the equation for estimating the time of preparation and cleaning works in terms of the cost of these works is as follows:

$$
\begin{gathered}
y_{1}=1.066 *\left(10^{-14}\right)-5.268 *\left(10^{-7}\right) x_{1} \\
+9.055 *\left(10^{-15}\right) x_{1}^{2}
\end{gathered}
$$

B-Earthworks.

Finding the equation that relates the cost of the Earthworks of road projects to the time of those works is done by choosing one from several equations (linear - quadratic - cubic), by testing the greater Fisher coefficient $(\mathrm{F})$ and the level of significance less than (0.01), found in the analysis table (ANOVA). Or through the scattering form directly, where the best-curved line chosen passes the points are drawn $[15,16]$.

Table 3. shows the value of the Pearson correlation coefficient $(+0.969)$, which means that the relationship between the two variables is a solid direct relationship and means that the time added in the change order increases with the increase of the cost of work in the same order.

Table 3.

ANOVA and Correlation Output, for Additional Earth Works.

\begin{tabular}{cccc}
\hline Equation type & Correlation coefficient & Fisher coefficient F & Significance \\
\hline Linear & +0.969 & 77.327 & Less than 0.01 \\
Quadratic & +0.969 & $1.394 * 10^{14}$ & Less than 0.01 \\
Cubic & +0.969 & - & - \\
\hline
\end{tabular}

Table 3. gives that the large $(\mathrm{F})$ value is for the quadratic equation and is equal to $\left(1.394^{*} 10^{14}\right)$. The significance value is less than (0.01), so the quadratic equation is chosen to represent the data of these works [15-17].

$$
y_{2}=a_{0}+a_{1} x_{2}+a_{2} x_{2}^{2}
$$

Where:

$\boldsymbol{y}_{2}$ : Time for Earthworks in change order (day).

$\boldsymbol{x}_{2}$ : Cost of Earthworks in change order (Iraqi dinar).

$$
\boldsymbol{a}_{0}, \boldsymbol{a}_{1, \text { and }} \boldsymbol{a}_{2}: \text { Equation coefficients }
$$

The (SPSS) program gives the values of $\left(\boldsymbol{a}_{0}, \boldsymbol{a}_{1, \text { and }} \boldsymbol{a}_{2}\right)$ after analysis and choosing the type of equation as follows:

$a_{0}=9.415 * 10^{-14}$

$$
\begin{aligned}
& a_{1}=1.6651 * 10^{-6} \\
& a_{2}=-2.1171 * 10^{-14}
\end{aligned}
$$

So, the equation for estimating the time of Earthworks in terms of the cost of these works is as follows:

$$
\begin{gathered}
y_{2}=9.415 *\left(10^{-14}\right)+1.6651 *\left(10^{-6}\right) x_{2} \\
-2.1171 *\left(10^{-14}\right) x_{2}^{2}
\end{gathered}
$$

C-Cladding works with asphalt or concrete layers.

Table 4. shows the value of the Pearson correlation coefficient $(+0.997)$, which means that the relationship between the two variables is a solid direct relationship and means that the time added in the change order increases with the increase in the cost of work in the same order. 


\section{Table 4.}

.ANOVA and Correlation Output, for Additional cladding of asphalt layers Works

\begin{tabular}{cccc}
\hline Equation type & Correlation coefficient & Fisher coefficient F & Significance \\
\hline Linear & & & Less than 0.01 \\
Quadratic & +.997 & 803.304 & - \\
Cubic & +.997 & - & - \\
\hline
\end{tabular}

Fig. 2. Give a more illustrative description of the curve that passes through the points drawn.

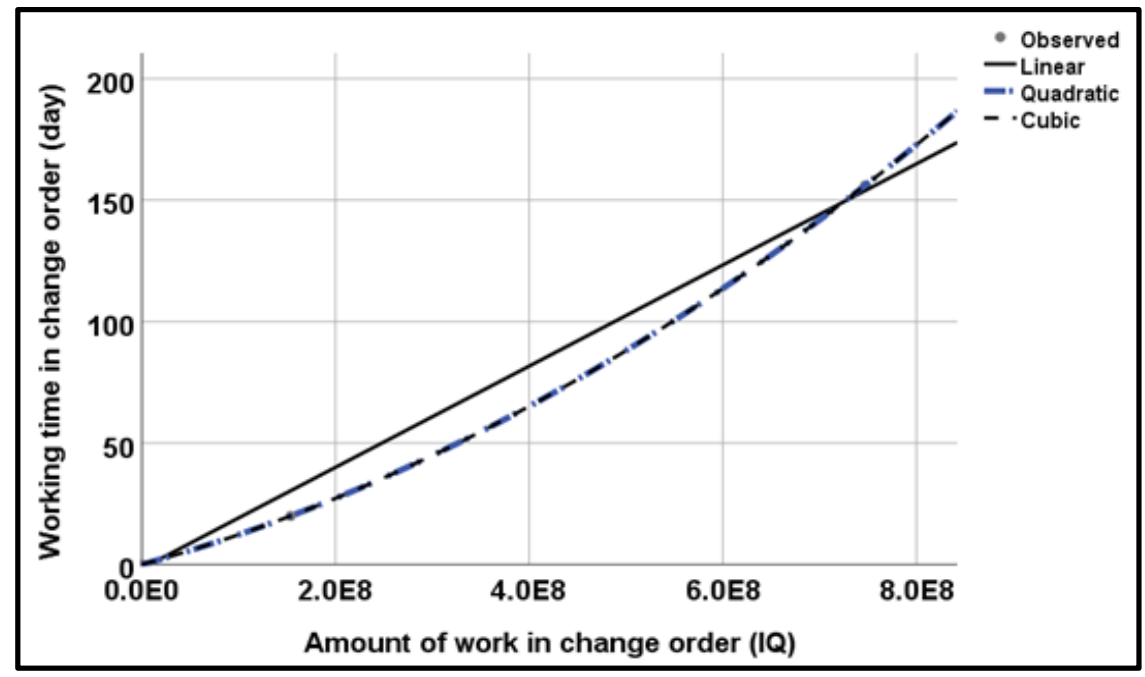

Fig.2. Scatter diagram for additional cladding of asphalt layers works, and it's time.

Fig.2. show that the curve of the third degree (cubic) is the closest and most passing through the points between the cost axis (X) and the time axis $(\mathrm{Y})$, so the equation of the curve is chosen from third degree (quadratic) to represent the data of these works [17], The equation of the curve is as follows:

$$
y_{3}=a_{0}+a_{1} x_{3}+a_{2} x_{3}^{2}+a_{3} x_{3}^{3}
$$

Where:

$\boldsymbol{y}_{3}$ : Time for Cladding works with asphalt or concrete layers works in change order (Day).

$x_{3}$ : Cost of Cladding works with asphalt or concrete layers works in change order (I.D.).

$a_{0}, a_{1}, a_{2, a n d} a_{3}$ : Equation coefficients
The (SPSS) program gives the values of $\left(\boldsymbol{a}_{0}, \boldsymbol{a}_{1, \text { and }} \boldsymbol{a}_{2}\right)$ after analysis and choosing the type of equation as follows:

$$
\begin{array}{ll}
a_{1}=1.097 * 10^{-7} a_{0}=-8.8818 * 10^{-15} \\
a_{3}=0 & a_{2}=1.33 * 10^{-16}
\end{array}
$$

So, the equation for estimating the time of Cladding with asphalt or concrete layers works in terms of the cost of these works is as follows:

$$
\begin{gathered}
y_{3}=-8.8818 *\left(10^{-15}\right)+1.097 *\left(10^{-7}\right) x_{3} \\
+1.33 *\left(10^{-16}\right) x_{3}^{2}
\end{gathered}
$$


D-Water drainage works.

As in the previous paragraphs, the equation required for estimating the time of water drainage works in terms of the cost of these works becomes as follows:

$$
y_{4}=2.581 *\left(10^{-7}\right) x_{4}
$$

Where:

$\boldsymbol{y}_{4}$ : Time for water drainage works in change order (Day).

$\boldsymbol{x}_{\mathbf{4}}$ : Cost of water drainage works in change order (I.D.).

E-Other works.
As in the previous paragraphs, the equation required for estimating the time of other works (The security checks works, security sonar works, and the works of equipping the resident engineer department) in terms of the cost of these works will be as follows:

$$
y_{5}=-5.55112 *\left(10^{-17}\right)+8.1301 *\left(10^{-7}\right) x_{5}
$$

Where:

$\boldsymbol{y}_{5}$ : Time for Other works in change order (Day).

$\boldsymbol{x}_{\mathbf{5}}$ : Cost of Other works in change order (I.D.).

Table 5. summarizes the formulae for determining the time of the additional and expected works in the change order.

Table 5.

\begin{tabular}{|c|c|c|}
\hline Seq. & Work type & Equation \\
\hline 1 & $\begin{array}{l}\text { Preparation and } \\
\text { cleaning work. }\end{array}$ & $y_{1}=1.066 *\left(10^{-14}\right)-5.268 *\left(10^{-7}\right) x_{1}+9.055 *\left(10^{-15}\right) x_{1}^{2}$ \\
\hline 2 & Earthworks. & $y_{2}=9.415 *\left(10^{-14}\right)+1.6651 *\left(10^{-6}\right) x_{2}-2.1171 *\left(10^{-14}\right) x_{2}^{2}$ \\
\hline 3 & $\begin{array}{l}\text { Cladding of } \\
\text { asphalt or } \\
\text { concrete layers. }\end{array}$ & $y_{3}=-8.8818 *\left(10^{-15}\right)+1.097 *\left(10^{-7}\right) x_{3}+1.33 *\left(10^{-16}\right) x_{3}^{2}$ \\
\hline $\begin{array}{l}4 \\
5\end{array}$ & $\begin{array}{l}\text { Sanitary works. } \\
\text { Other works. }\end{array}$ & $\begin{array}{c}y_{4}=2.581 *\left(10^{-7}\right) x_{4} \\
y_{5}=-5.55112 *\left(10^{-17}\right)+8.1301 *\left(10^{-7}\right) x_{5}\end{array}$ \\
\hline
\end{tabular}

Summary of the added work equations.

The analysis also revealed the most common work in the change orders of road projects. Preparation and cleaning works were repeated at a rate of $30 \%$, while Earthworks were repeated at $20 \%$, which is the same proportion as water drainage works.

\section{Computer program.}

The program (Modeling to determine the effect of a change order for road projects on execution time) is intended to make the usage of these equations easier. The computer is programmed in the $(\mathrm{C \#})$ programming language and runs in the (Visual Basic) environment. The program is opened, then select the type of work to calculate the time required for its implementation. The change order's cost (in Iraqi dinars) is entered, as well as the time it will take to complete the work (per day). Fig. 3-4. depicts this.

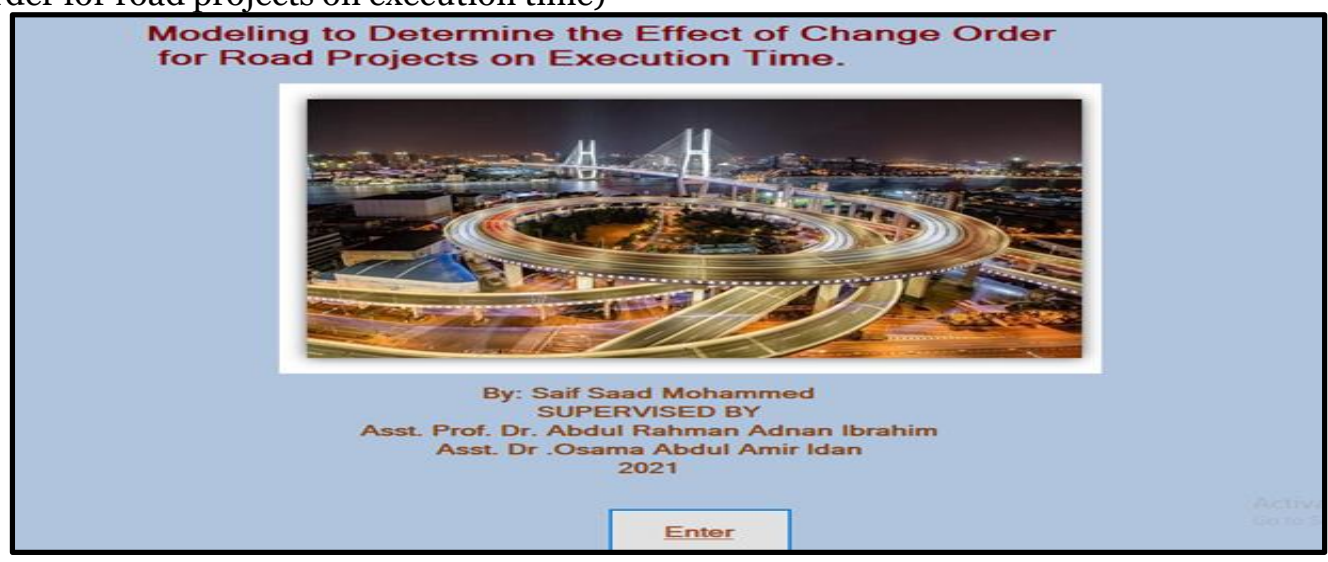

Fig. 3. shows how to enter the program 


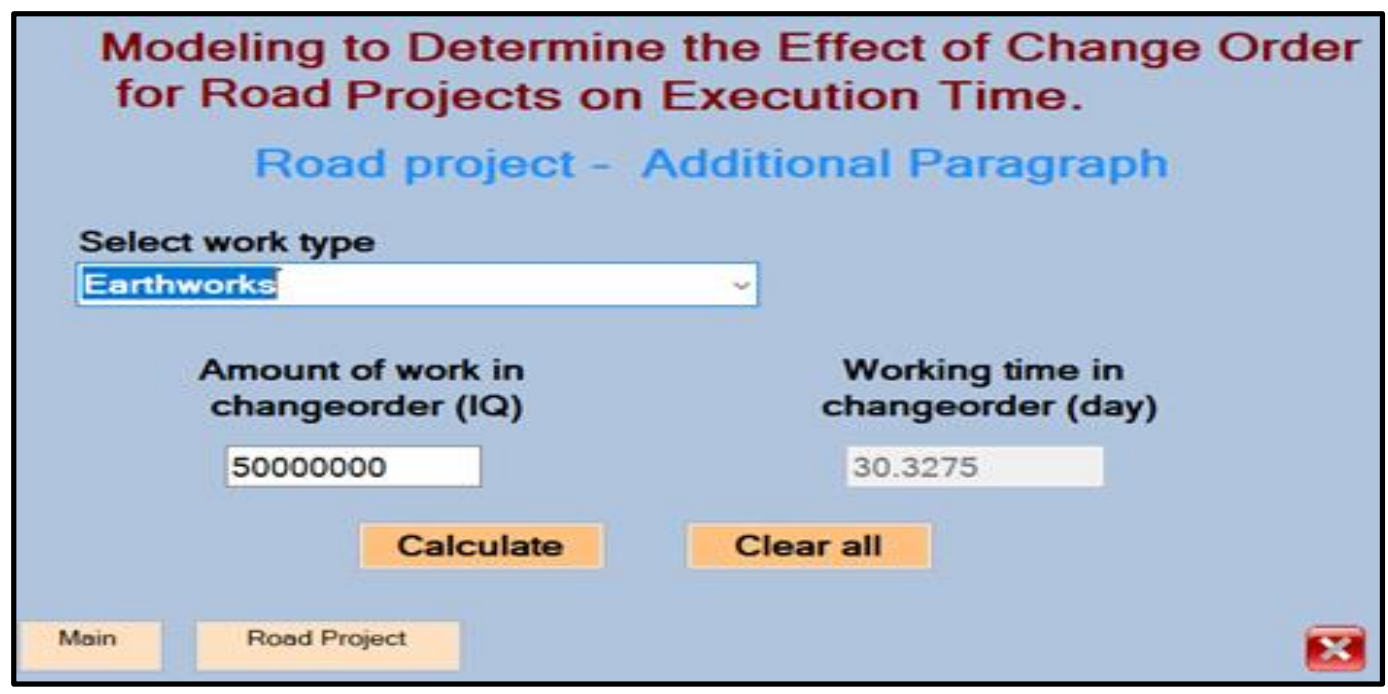

Fig.4. shows the calculation of working time in terms of cost.

The program was evaluated by presenting it to a group of sixteen engineers working on road projects. The program assessed (very good) practical benefit by (50\%) of the evaluated engineers. It also received a (good) evaluation in terms of benefiting from the program in future projects by (49.8\%) of the assessed engineers

\section{Conclusions.}

The causes of change orders and their effects on project schedules are complex and influenced by numerous interrelated factors. The objective of this research study was to carry out a literature review and field survey to create a computer program that estimates the time required to complete the additional work due to the change command by evaluating the cost of these works. Also, to find out the most frequent words in change orders for road projects at Salah al-Din Governorate. Based on the field survey conducted and the results found, the following can be concluded and outlined:

1- There is a close relationship between the cost of road project works in the change order and the time required to implement these works, as the latter increases with the increase in cost.

2- The most frequent works in change orders for road projects at Salah al-Din Governorate has been specified and concluded. It was found that the works of operating and cleaning roads were repeated at a rate of $(30 \%)$ in the change orders. Moreover, the earthworks were repeated at a rate of $(20 \%)$, and the drainage works were repeated at (20\%). These results are used to focus on these works when preparing quantities for future projects to avoid errors in estimating quantities and the problem of increasing time and cost resulting from change orders of these projects.

3- The easiest way to avoid time delays caused by change order work is to avoid creating the change order from the beginning. This is accomplished by concentrating on the design stage, preparing bills of quantities, and more accurately determining the required amounts.

\section{References.}

[1] Alaryan A, Emadelbeltagi AE, Dawood M. Causes and effects of change orders on construction projects in Kuwait. International Journal of Engineering Research and Applications. 2014, 4(7), 1-8.

[2] Gokulkarthi M, Gowrishankar KS. A study on impacts of a change order in construction projects. International Journal of Science and Engineering Research. 2015, 3(4).

[3] Memon AH, Rahman IA, Hasan MF. Significant causes and effects of variation orders in construction projects. Research Journal of Applied Sciences, Engineering and Technology. 2014, 7(21): 4494-4502.

[4] Eigbe S. Empirical Study of the Origins and Causes of Variation Orders in Building Projects. International Journal of Engineering Research and Applications. 2016, 6(10), 34-48.

[5] Shrestha PP, Zeleke H. Effect of change orders on cost and schedule overruns of school building renovation projects. Journal of Legal Affairs and Dispute Resolution in Engineering and Construction. 2018, 1O(4), 04518018.

[6] Staiti M, Othman M, Jaaron AA. Impact of change orders in construction sector in the 
West Bank. International conference on industrial engineering and operations management. 2016, March: (pp. 16901698).

[7] Maher M, Mahmoud Hariri. Study the causes of change orders and how to avoid their negative impact on construction projects. Tishreen University Journal-Engineering Sciences Series. 2015, 37(3).

[8] Ahmed S, Hasan B, Jrad F, Dlask P. Analyzing the Change Orders Impact on Building Projects. Journal of Engineering and Applied Sciences. 2016, 11(7): 1532-1537.

[9] Karthick R, Malathi B, Umarani C. Study on change order impact on project lifecycle. International Journal of Engineering Research \& Technology. 2015, 4(5): 691-695.

[10] Mahmoud SY, Elshaikh EA. The Potential Effects of Variation Orders on Building Projects in Khartoum StateSudan. International Journal of Construction Engineering and Management. 2019, 8(2), 70-79.

[11] Hassana AJ, Abd RS, Jon HH. Cost risk management for variation orders in road projects in Iraq. Engineering and Technology Journal. 2020, 38(2A): 166172.

[12] Al-hams MF. Simulation model of change orders and their impact on building projects performance in Gaza strip. 2010.

[13] Raposo F. Evaluation of analytical calibration based on least-squares linear regression for instrumental techniques: A tutorial review. TrAC Trends in Analytical Chemistry. 2016, 77, 167-185.

[14] Cohen P, West SG, Aiken LS. Applied multiple regression/correlation analysis for the behavioral sciences. Psychology press. 2014.

[15] Magar VM, Shinde VB. Application of 7 quality control (7 QC) tools for continuous improvement of manufacturing processes. International Journal of Engineering Research and General Science. 2014, 2(4): 364-371.

[16] Roberts M, Russo R. A student's guide to analysis of variance. Routledge. 2014.

[17] Chatfield C. Statistics for technology: a course in applied statistics. Routledge. 2018. 